\title{
Acetylcholine Test for Anhydrosis in Leprosy
}

\author{
PARIKH, A. C.*, GANAPATI, R.†, \\ KAPADIA, B. I., $\ddagger$ and NAIK, S. S. $\ddagger$
}

Since Father Joseph Damien de Veuster's observation in 1889 that on the early macules of leprosy which appeared on his own skin perspiration did not appear, many authors were inspired to investigate this localized anhydrosis in early patches of leprosy and also utilize this phenomenon for early diagnosis of the disease especially where the examination for the cardinal signs of leprosy gave doubtful results.

\section{Physiology of sweat secretion}

The physiology of sweat secretion is a complex matter. The sweat gland structures are supplied by the non-medullated sympathetic fibres, which form a close plexus on the outer surface and give off fibrils to the glandular and muscular cells. Unlike other sympathetic innervated structures they are not 'adrenergic' but are 'cholinergic'.

Anhydrosis, partial or absolute, may be due to deficiency, destruction or absence of the secretory apparatus.

It may result from congenital ectodermal defects and may be associated with other physical characteristics showing:

I. symmetric volar keratosis with follicular keratosis of the body.

2. keratosis of hands, feet and body with leukoplakia of mouth or

3. these changes combined with corneal alternation or cataract.

Localized anhydrosis may occur due to a variety of causes leading from disorders of the nervous system to the skin lesions. The anhydrosis is symptomatic in ichthyosis, ectodermal defects, extensive psoriasis, scleroderma, morphea, other cicatricial lesions including roentgen dermatitis, avitaminosis A, neuritis and leprosy.

\section{Intradermal Tests}

Anhydrosis resulting from the early denervation of sweat glands supplied by the cholinergic post- ganglionic sympathetic fibres, due to neuritis of leprosy has led many authors to devise intradermal sweat tests (sudomotor tests) for the early diagnosis of leprosy.

As pilomotor and vasomotor responses also seem to be affected in this way, a series of intradermal tests are available as diagnostic aids.

The following are the more important of these:

Sudomotor Tests :

(a) Pilocarpine nitrate, (Dubois \& Degotte, I 938).

(b) Metacholine, (Arnold, I948).

(c) Adrenaline, (Wada, I950).

Pilomotor Test: Nicotine Picrate (Arnold, I953); (Rothman, I953).

Vasomotor Test: Histamine (Rodriguez and Plantilla, I 933).

It is not proposed to go into the relative merits of these various tests, as the majority of these are not being used widely either because they cannot be interpreted satisfactorily or these tests are positive in other dermatological conditions such as achromia parasitica, mycotic infection, scleroderma, morphea etc. It is also debatable whether the affection of sympathetic fibres occurs before the other fibres subserving heat, touch and pain sensations are affected by $M$. leprae. According to Arnold (1948) impairment of the sweat function precedes the development of demonstrable anaesthesia.

\section{Aim of the Study}

The increasing need for early diagnosis of leprosy among hypopigmented lesions due to various causes prompted us to study whether any simple and better intradermal test will be of

* Medical Officer, $\dagger$ Research Officer, $¥$ Research Assistants, Acworth Leprosy Hospital, Wadala, Bombay 3 I, (INDIA).

Paper read at the 8th All India Conference of the Indian Association of Dermatologists \& Venereologists held at Gwalior in January 1966.

Acetylcholine Test for Anhydrosis in Leprosy $23 \mathrm{I}$ 
help as a diagnostic aid, as a considerable number of such cases have to be kept under observation without arriving at a diagnosis for want of unequivocal demonstration of the cardinal signs of leprosy.

\section{Material}

The study was made in I59 patients who attended the clinic of the Acworth Leprosy Hospital, Bombay, with hypopigmented lesions. Of these, 87 patients had well developed characteristic lesions of leprosy where the cardinal signs could be easily elicited and hence a diagnosis of leprosy could be made. Out of these 87 patients, 9 had multiple lesions some of which had no anaesthesia. In all, the lesions studied number 96 in 87 patients. These act as a control for the study of the test. The remaining 72 patients had hypopigmented lesions of doubtful origin which simulated early leprosy as well as other skin diseases or conditions.

\section{Method}

After routine clinical and bacteriological examinations for the cardinal signs of leprosy, sweat test with intradermal acetylcholine was performed in all the cases.

Sweat Function Test:

Materials used: ( I) Acetylcholine (0.I\% aqueous solution).

(2) Bromophenol blue paper.

Bromophenol blue paper is made as follows: I OO mgm. of bromophenol blue powder is dissolved in $\mathrm{s}$ cc. of absolute alcohol to make a I \% solution. The solution is poured on a Whatman filter paper no. 4 with the help of a pipette. The paper is allowed to dry and cut into square pieces of I" $\mathrm{X} \mathrm{I}^{\prime \prime}$.

Method:

The lesion and a corresponding area of the skin on the other side which is normal are cleaned with spirit.

Acetylcholine $(0 \cdot \mathrm{I} \%$ aqueous solution $)$ is injected intradermaly in both the areas with a tuberculin syringe. $0.05 \mathrm{ml}$. is injected in each area. The droplets of solution that leak out from the injected sites are gently blotted off.

After 2 minutes 2 square pieces of bromophenol blue paper (which are actually yellow in colour) are pressed lightly on the sites of injection for 15 seconds and removed.
The sweat drops appear on the paper as blue dots. Interpretation of the test:

I. Normal: Number of blue spots close to each other with no appreciable difference as compared to the normal or control area. (Fig. I).

2. Slightly diminished: Number of spots more than half but yet less than in the normal or control area. (Fig. 2).

3. Markedly diminished: Number of blue spots less than half the number found in the normal or control area. (Fig. 3).

4. Absence of sweating: No blue spots on the paper. (Fig. 4).
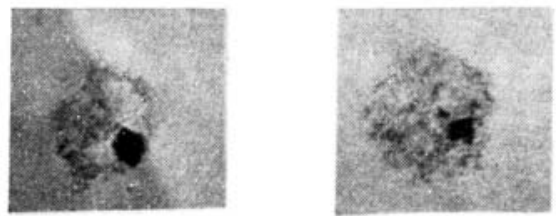

Fig. 1.

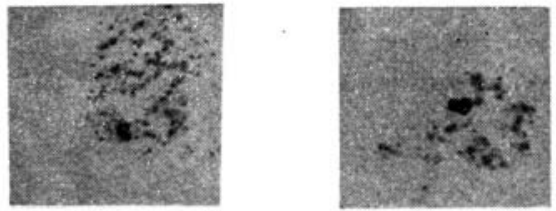

Fig. 2.

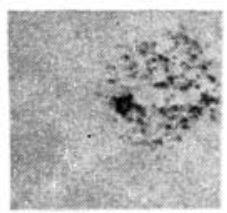

Fig. 3.

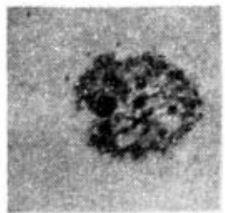

Fig. 4.
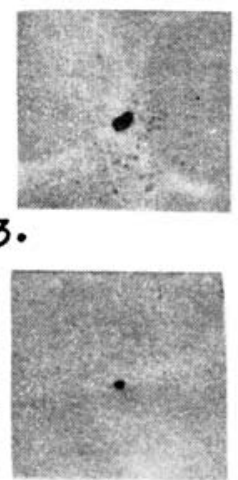

Bromphenol blue papers showing spots of sweat. The papers on the left represent the normal (Control) and those on the left the lesions.

\section{Leprosy Review}




\begin{tabular}{lccccc}
\hline & & \multicolumn{4}{c}{ RESUlts OF SWEAT TEST } \\
\cline { 3 - 6 } Sensory changes & Total & Normal & $\begin{array}{c}\text { Slightly } \\
\text { Diminished }\end{array}$ & $\begin{array}{c}\text { Markedly } \\
\text { Diminished }\end{array}$ & Absent \\
\hline Anaesthesia & 4 I & I & - & I & 26 \\
Hypoesthesia & 46 & 2 & 7 & 2 I & I 6 \\
No anaesthesia & 9 & 3 & I & 4 & I \\
\hline Total: & 96 & 6 & 8 & 39 & 43 \\
\hline
\end{tabular}

\section{RESULTS}

I. Lesions due to Leprosy (Control group).

Table I shows the results of sweat test in 96 anaesthetic as well as non-anaesthetic hypopigmented lesions of 87 leprosy patients of tuberculoid and maculo-anaesthetic type.

It will be seen from the table that out of 87 lesions which showed definite sensory impairment, diminution or absence of sweating could be demonstrated in $84(96 \cdot 6 \%)$ and only 3 lesions showed normal sweating. Out of 9 non-anaesthetic lesions, $6(66 \cdot 6 \%)$ had diminished sweating, while 3 showed normal sweat response.

Lesions of 'Indeterminate' leprosy (of the intermediate group) and lepromatous macules were not included in the present study as these lesions are bacteriologically positive for large numbers of bacilli and hence are easily diagnosed. (However, it may be stated that in two cases of leprosy of the 'Indeterminate' type in which the sweat test was done the lesions showed appreciable diminution of sweating.)

\section{Lesions simulating early leprosy}

Seventy-two patients had hypopigmented lesions resembling leprosy in which a diagnosis could not be arrived at af ter routine standard methods of examination. Histopathological examination was done in all these cases.

Out of these 72,28 patients showed early infiltrative changes of a nonspecific nature sug- gestive of leprosy, as described by Khanolkar ( 1964), Dharmendra ( I96o), Ridley and Wise (1963) and Hasselmann ( 1963). The following criteria were considered for labelling biopsy slides as those showing nonspecific changes:

(i) Epidermis showing atrophy and narrowing of stratum malpighii or prickle cell layer with varying degrees of flattening of the rete-pegs.

(ii) Dermis showing infiltrative exudates predominently composed of lymphocytes, histiocytes and fibroblasts concentrated more around the pilosebaceous apparatus, sweat glands and neurovascular channels, with or without evidence of histiocytic granuloma in the formative stages.

Thirty-five patients showed more specific histological features of leprosy described by Khanolkar ( I964) and Lever (I96i). The following features were taken into consideration to grade cases into those showing 'specific' histology of leprosy:

(i) Chronic tuberculoid granuloma in the dermis with epithelioid cells and giant cells.

(ii) Evidence of infiltrated or destroyed nerves.

Nine patients showed features suggestive of diseases other than leprosy, namely allergic dermatitis (5 cases), secondary syphilis (2 patients), lupus erythematosus and scleroderma (one each). 
The results of sweat tests performed on these 72 patches are as follows:

TABLE 2

\begin{tabular}{lcc}
\hline Result of sweat Test & No. of patients & Percentage \\
\hline Normal & I $~$ & $23 \cdot 6$ \\
Slightly diminished & I 2 & I $6 \cdot 7$ \\
Markedly diminished & 32 & $44 \cdot 4$ \\
Absent & I I & I5 $5 \cdot 3$ \\
\hline Total: & 72 & I $00 \cdot 0$ \\
\hline
\end{tabular}

It will be seen that $59 \cdot 7 \%$ of the patients had either marked impairment or complete absence. I $6 \cdot 7 \%$ showed slight impairment and sweating was normal in $23 \cdot 6 \%$.

\section{DISCUSSION}

It may be concluded from the above results that in the lesions of the tuberculoid and maculoanaesthetic type of leprosy showing definite sensory changes, anhydrosis can be demonstra- ted by the intradermal sweat test to the extent of $96 \cdot 6 \%$.

The majority of lesions which clinically simulate early leprosy but which have to be kept under observation for want of unequivocal demonstration of cardinal signs, have shown not only impairment of sweat function in varying degrees but also very early histological changes suggestive of leprosy.

TABLE 3

\begin{tabular}{|c|c|c|c|c|c|}
\hline \multirow{2}{*}{$\begin{array}{l}\text { Histopathological } \\
\text { Changes }\end{array}$} & \multirow{2}{*}{ Total } & \multicolumn{4}{|c|}{ RESULTS OF SWEAT TEST } \\
\hline & & Normal & $\begin{array}{c}\text { Slightly } \\
\text { Diminished }\end{array}$ & $\begin{array}{l}\text { Markedly } \\
\text { Diminished }\end{array}$ & Absent \\
\hline Non-Specific for leprosy & 28 & 7 & 5 & I 2 & 4 \\
\hline Specific for leprosy & 35 & 6 & 6 & I 6 & 7 \\
\hline Allergic Dermatitis & 5 & 2 & I & 2 & - \\
\hline Secondary syphilis & 2 & I & - & I & - \\
\hline Lupus Erythematosus & $\mathbf{I}$ & I & - & - & - \\
\hline Scleroderma & I & I & - & - & - \\
\hline
\end{tabular}

Table 3 shows the correlation between histological findings and sweat tests in 72 patients where the cardinal signs of leprosy could not be elicited.

It will be seen that out of the 63 patients who were histologically suggestive of leprosy, $5^{\circ}$ $(79 \cdot 4 \%)$ showed definite diminution of sweat function and 13 patients $(20.6 \%)$ had normal sweating.
In three patients of allergic dermatitis, and in one patient with secondary syphilitic lesions also, normal sweating could not be detected with acetylcholine test.

Arnold (1948) has also found confusing results (diminished or absent sweating) in 4 or 5 conditions for which leprosy is apt to be mistaken. The sweat response is liable to be absent in the oval, hypopigmented, facial macules of so 
called 'achromia parasitica'. He also states that histologically such patients show nothing to suggest leprosy and the great majority of such patches disappear after external application of either ammoniated mercury ointment or White's crude coal tar paste.

Our experience of sweat tests in similar patches has been the same; but when such patients were asked to apply antifungal ointment containing coal tar or hydroxy-quinoline derivative, the majority of these patches disappeared within about three weeks and sweat function returned to normal.

However, there are some drawbacks of sweat tests in general, as one has to make physiological allowance for varying amounts of sweating in different sites of the body owing to an unequal distribution of eccrine sweat glands. The function of the glands also diminishes with old age. However, these difficulties are obviated to some extent by choosing a control site in the opposite half of the body and by increasing the quantity of acetylcholine injected, (if necessary a maximum $\mathrm{o} \cdot \mathrm{I} \mathrm{ml}$. can be used in sites where sweat response is expected to be less).

In this study acetylcholine was used intradermally to induce sweating and bromophenol blue paper for the demonstration of sweat, whereas Arnold has recommended the use of mecholyl, a beta-methyl derivative of acetycholine to stimulate the sweat glands and Minor's Iodine solution with starch for the detection of sweat. Mecholyl was not available for this study and acetylcholine solution was found quite stable and adequate for the purpose. In this study bromophenol blue paper method was found much superior for the demonstration of sweat, as the blue spots can be observed, on a yellow background with photographic clarity.

The intradermal test, by virtue of the fact that it is extremely simple to perform and easy to read (in its present modified form) has been found very useful to detect anhydrosis in lesions suggestive of leprosy.

Considering the limitations of the sweat test, one has to take into consideration the histopathological evidences of early leprosy in the diagnosis of hypopigmented lesions. In view of the consistent anhydrosis and characteristic histological features suggestive of early leprosy observed in the hypopigmented lesions studied in this investigation, it was thought necessary to see if any correlation existed between the anhydrosis as detected by this test and the histological appearance of sweat glands.

The following table shows the correlation between these two features in the 72 doubtful patients :

It will be seen from the table below that out of 56 patients having diminished sweat response $48(85 \cdot 7 \%)$ showed either chronic inflammatory cells in relation to sweat glands, or infiltrative destruction and atrophy of glands. Out of 16 patients in whom sweating was normal, $9(56 \cdot 3 \%)$ showed infiltration around the glands.

Sato (1938) has described both atrophy of glands (in simple macules and in skin which is merely anaesthetic) and infiltrative destruction of them (in elevated tuberculoid lesions). These observations could not be confirmed by later workers. According to Arnold ( I 948), visible damage to the glands could only occasionally be seen in tuberculoid lesions and rarely in simple macules.

It is not possible from our figures to conclude that impaired sweat function is invariably accompanied by histological changes of the sweat glands, though in the majority of the patients showing infiltrative or destructive

TABLE 4

\begin{tabular}{|c|c|c|c|c|c|}
\hline \multirow{2}{*}{ Sre'eat Test } & \multirow{2}{*}{ Total } & \multicolumn{4}{|c|}{ HISTOLOGICAL APPEARANCE OF SWEAT GLANDS } \\
\hline & & Normal & $\begin{array}{l}\text { Infiltration } \\
\text { around glands }\end{array}$ & $\begin{array}{l}\text { Atrophy or } \\
\text { Destruction } \\
\text { of glands }\end{array}$ & $\begin{array}{c}\text { No gland } \\
\text { seen in } \\
\text { bioposy }\end{array}$ \\
\hline Normal & I 6 & 6 & 9 & - & I \\
\hline Diminished & $5^{6}$ & 6 & $4^{2}$ & 6 & 2 \\
\hline Total & 72 & I 2 & $5 \mathrm{I}$ & 6 & 3 \\
\hline
\end{tabular}


changes of sweat glands, the secretory function of the glands seems to be affected.

Our findings, namely that $96 \cdot 6 \%$ of lesions caused by leprosy and $79.4 \%$ of those clinically and histopathologically suggestive of leprosy but without definite sensory impairment show diminished sweat response to intradermal acetylcholine may be considered as substantiating Arnold's suggestion that abnormal sweat response probably precedes the onset of demonstrable sensory changes. According to Figueredo and Martins ( I959) the earliest visible sign of leprosy (primary lesion) is a hypopigmented or erythematous macule without sensory changes. In a comprehensive study which included a five year follow-up of 500 contacts of leprosy patients these authors observed development of lesions (without sensory impairment) in 73 contacts which remained static for variable periods of time, some of them finally vanishing. In io patients diagnosis could be confirmed histologically. It is obvious that one is likely to miss early diagnosis of leprosy if a thorough investigation is not done.

Where there is no anaesthesia, no single test by itself can be considered diagnostic of leprosy unless the lesion is positive for acid fast bacilli. Hence it is suggested that in all cases where clinical and bacteriological examinations have given inconclusive results, intradermal sweat test should be performed. Positive findings are of great significance when correlated with even non-specific histological features suggestive of early leprosy.

\section{SUMMARY}

A simple method to detect anhydrosis using $\mathrm{O} \cdot \mathrm{I} \%$ acetylcholine and bromophenol blue paper has been described.

In a study of I 59 patients, anhydrosis has been demonstrated using this test in $96 \cdot 6 \%$ of lesions caused by leprosy diagnosed by routine standard methods and $79.4 \%$ of those clinically and histopathologically suggestive of leprosy, but without definite sensory impairment.

As histological changes in relation to the sweat glands have been observed in the majority of hypopigmented lesions suggestive of leprosy in which anhydrosis could be demonstrated, it may be concluded that abnormal sweat response resulting from denervation of sweat glands due to neuritis due to leprosy probably precedes the development of demonstrable sensory changes.

\section{GONCLUSIONS}

I. A n intradermal acetylcholine test to detect anhydrosis is extremely simple to perform and easy to read in the modified form as described.

2. It is recommended as a useful auxiliary diagnostic aid in leprosy where a diagnosis cannot be arrived at by clinical and bacteriological examinations only.

3. Using this test and histopathological examinations, it is possible to conclude that abnormal sweat response resulting from denervation of sweat glands due to neuritis due to leprosy probably precedes the onset of demonstrable sensory changes.

\section{A GKNOWLEDGEMENT}

We are grateful to Dr N. Figueredo, Special Officer, Acworth Leprosy Hospital, Wadala, Bombay 3I, India, of international repute for his invaluable guidance in the conduct of this investigation and the preparation of this paper.

We are also thankful to Dr N. I). Katdare, Superintendent, Acworth Leprosy Hospital, Wadala, Bombay 3 I, India, for allowing us to present this paper and for his guidance.

\section{REFERENCES}

ARNOLD, H. L., JR (1948), 'The intradermal mecholyl test for anhydrosis, a diagnostic aid in leprosy', Internat. 7 . Leprosy : r6, 335 .

ARNOLD, H. L., JR (I953), 'The pilomotor response to intradermally injected micotine; an aid in excluding the diagnosis of leprosy', Internat. 7. Leprosy : 21, i 69.

DharmenisRa ( 1 960), 'Notes on Leprosy', p. 42, 'The Ministry of Health, Government of India.

Dubois, A. and Degotte, J. (1938), Quoted by Khanolkar (1955), 'Perspectives in Pathology of Leprosy', Ind. 7. Med. Sci., 9, (supplement I) : p. 28.

Figueredo, N. and martins, A. B. (I 959), 'Genesis of Leprosy Lesions', Ind. 7. Med. Res., 47, 622.

hasselmann, C. м. (1963), 'Histopathology in early Leprosy', abst. Internat. 7. Leprosy : 31, $5^{1} 6$. 
KHANOLKaR, V. R. (I964), 'Leprosy in Theory and Practice', (Ed. R. G. Cochrane \& T. F. Davey), 2nd Ed., Ch. VIII, pp. I26, I36, I37, I38, Bristol : John Wright \& Sons Ltd.

LeVer, WAlter F. (I96i), 'Histopathology of the Skin', 3rd Ed., p. 244, London : Pitman Medical Publishing Co. Ltd.

RIDLEY, D. S. and WiSE. M. J. (1964), 'Reaction of the Dermis in Leprosy', Internat. 7. Leprosy, $3^{2}: 24$.
RODRiguez, J. and Plantilla, F. c. ( I 933), 'The Histamine Test as an Aid in the Diagnosis of Early Leprosy', Internat. 7. Leprosy, r, 49 .

rothman, s. (1953), Quoted by Arnold (1953).

sAto, s. (1938), 'Zur morphologischen studie der schweissdrusen bei Lepra', Japanese Jour. Dermat \& Urol. 43, 107 (abst. Internat. 7. Leprosy : 8, 546, i 940).

WADA, м. (1950), 'Sudorific Action of Adrenalin on the Human sweat glands and Determination of their Excitability', Science, III : 376 . 